\title{
Climate effects on grape production and quality at Kumeu, New Zealand
}

\author{
$\underline{\text { S Shanmuganathan }}^{\mathrm{a}}$, J Whalley ${ }^{\mathrm{ab}}$ and A. Perez-Kuroki ${ }^{\mathrm{a}}$ \\ ${ }^{\mathrm{a}}$ Geoinformatics Research Centre (GRC), \\ ${ }^{\mathrm{a}} \mathrm{S}$ chool of Computing and Mathematical Science (SCMS), \\ Auckland University of Technology (AUT), New Zealand \\ Email: subana.shanmuganathan@aut.ac.nz
}

\begin{abstract}
Grape quality and anticipated berry composition (Brix, flavour and aroma) significantly vary due to the variability in seasonal climatic and environmental conditions, such as soil and topography within vineyards. Such "Meso" climatic and "terroir" variations affect grapevine phenology (from bud formation to berry ripening stages). This in turn affects productivity, some instances extensively, in terms of total vine yield, grape bunch count, berry weight and composition even within a vineyard. Quantifying these effects on grape production and quality has been a challenging task as no detailed study has been performed at precision agricultural level for this vineyard located in Kumeu, New Zealand. This study investigates the influences of climate and soil components on the production of this vineyard using data gathered from 2011 to 2013.
\end{abstract}

Field monitoring conducted for the years 2011 and 2013 included soil sampling at strategic locations (figure 1), grape bunch and berry sampling for measuring bunch count, total weight and Brix (sugar) content in berry samples from the same specific sites for the two grape varieties (Chardonnay and Pinot Noir) planted in the vineyard. Unusually severe frost events were recorded in September 2012 in Kumeu, which affected the early developmental stages of the grapes significantly in many vineyards and this has resulted in observable decreases in productivity.

Preliminary results show a substantial difference between the crops harvested for the studied years, which is an indication of the damage caused by the abnormally severe frost experienced in the region in the beginning of the growing season. It warrants further investigation to understand the influences of topographic features which are either protective or damaging to the vine, especially the young buds.

The spatial analysis of topographic features, combined with plant production and soil nutrient composition identifies the damage prone areas. This information will be useful for any future investigations on possible mitigation strategies to protect vulnerable zones.

Keywords: Soil nutrient, grapevine, geostatistical analysis: hot spot analysis, explanatory regression, ordinary least square regression.

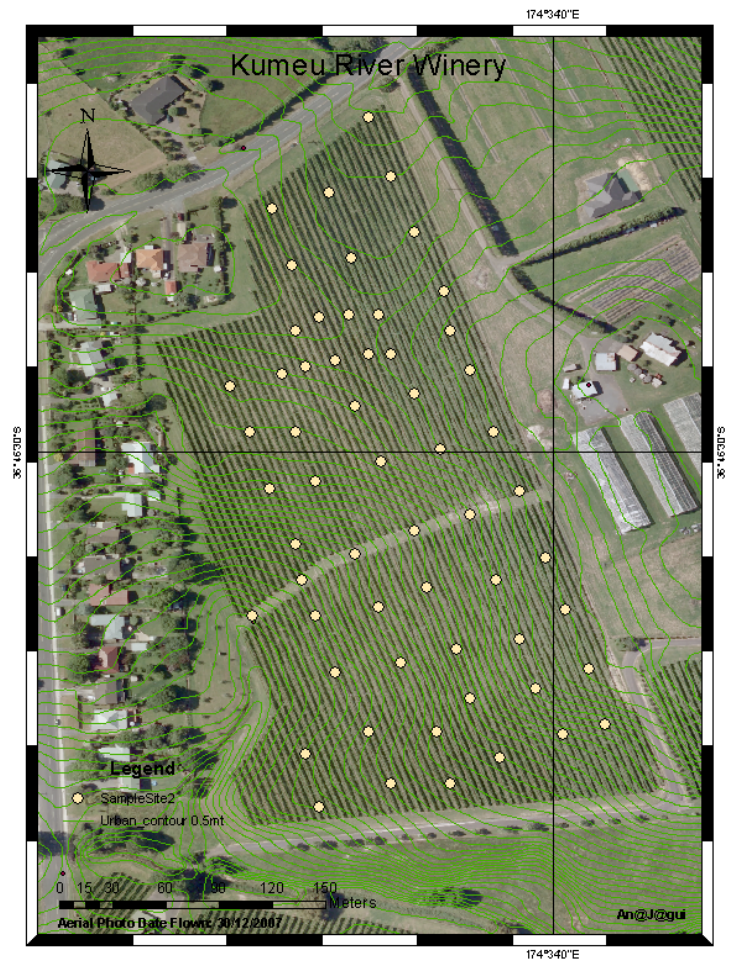

Figure 1. Map showing the soil, grape bunch and berry sampling sites from 2009-2013 Data on soil nutrients ( $\mathrm{Na}, \mathrm{K}, \mathrm{NO} 3$ and $\mathrm{pH}$ ), grape bunch and berry composition from these sites were analysed using geostatistical methods and the results show the subtle spatial variability within the vineyard in Kumeu (36 46'30"S 174 $\left.34^{\circ} 0^{\prime \prime} \mathrm{E}\right)$, Auckland, New Zealand 


\section{INTRODUCTION}

Many recent studies have highlighted the potential for using precision viticulture (PV) techniques for targeted management of wine grape production. The potential quality of wine is said to be "established in the vineyard and carried to fruition in the winery" (Bramley, et al., 2011:1). Lately, the harvest targets have been extended from just yield to vine disease status, berry damage and development in terms of $\mathrm{pH}$, acidity,

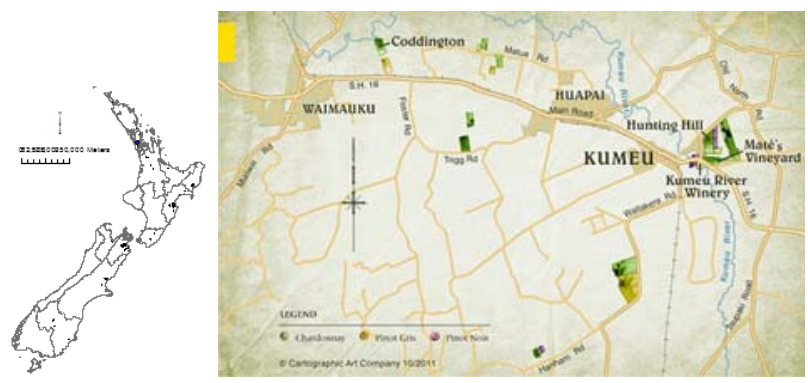

Figure 2. Maps showing New Zealand, Kumeu River Wines vineyards and grapevine varieties cultivated. soluble solids and colour. More recently even flavour and aroma have been included in the equation. Increasingly, PV techniques are deployed to analyse the underlying characteristics of the land, such as soil and topography, to gain further knowledge on the spatial variability within the vineyard (Shanmuganathan, et al., 2011).

In a previous study, Perez-Kuroki, et al., (2011), analysed data on soil composition and total yield from a vineyard in Kumeu, West Auckland, New Zealand using conventional statistical methods, such as regression techniques. In this work more data on soil, yield and elevation from the same vineyard was analysed incorporated into a GIS and with geostatistical methods to establish the spatial variability in the vineyard. Section 2 gives a background on the vineyard location and grapevine varieties cultivated. In section 3 data used and methodology adopted are elaborated. The results obtained are discussed in section 4 and in the final section, some conclusions are summarised.

\section{KUMEU RIVER WINES}

Vineyards of Kumeu River Wines located in the West of Auckland in northern New Zealand (figure 2) were established in the 1940s. The 30 hectares of vineyards (figure 2) are predominantly of clay soils overlying a sandstone base. These soil types retain sufficient water at depth even during the summer months hence the deep vine roots get a sufficient supply of moisture. Because of this the vineyard does not require irrigation, a factor that is critical to the quality of Kumeu River region grapes. Even though the region is the northern most of New Zealand's wine regions, the Kumeu climate is still described as "cool" due to its close proximity to both the Tasman Sea in the west and the Pacific Ocean in the east. The region's climate is moderated by the clouds generated by the surrounding seas so even in summer the region's temperature is generally below $30^{\circ} \mathrm{C}$. The conditions significantly enhance the somewhat unique aromas and flavours for the early ripening varieties such as Chardonnay, Pinot Gris and Pinot Noir cultivated in Kumeu River Wines (http://www.kumeuriver.co.nz/Our-Vineyard/). The soil and grape samples from one of these vineyards (5.2ha) planted with Chardonnay and Pinot Noir vines were collected.

\section{THE METHODOLOGY}

The soil sampling techniques, soil nutrient analyses performed and grape bunch/ berry collection methods and berry composition tests conducted are outlined in this section.

\subsection{Soil sampling and analysis}

Soil samples collected were dried and analysed to find the concentrations of vital soil nutrients required for plant growth. Both the soil and bunch/berry sampling details are listed in table 1. The grapevine varieties planted in the vineyard are: Chardonnay and Pinot Noir.

Physical and chemical tests were performed on 137 soil samples
Table 1.Soil and grape bunch/berry sampling details

\begin{tabular}{|l|l|l|}
\hline sample & details & tests/ analysis \\
\hline Soil & $\begin{array}{l}\text { Samples from three different depths } \\
\text { (figure 3: A (5 15cm depth), } \\
(15 \sim 25 \mathrm{~cm} \text { depth) and C (25 35cm } \\
\text { depth) at locations shown in map of } \\
\text { figure were taken for analysis of } \\
\text { physical and chemical properties. In } \\
\text { field pH and temperature were recorded } \\
\text { at the time of sample collection }\end{array}$ & $\begin{array}{l}\text { In-field; } \mathrm{pH} \text {, temperature } \\
\text { Lab: Na, K, Ca and NO3 }\end{array}$ \\
\hline $\begin{array}{l}\text { Grape } \\
\text { bunch }\end{array}$ & $\begin{array}{l}\text { Bunches/ vine were recorded for the } \\
\text { four vines next the soil sampling sites } \\
\text { (figure 1). In total 152 vines, out of } \\
12793(\sim 1.2 \% \text { of the 5.2ha } \\
\text { x2460vines/ha) were used in this study. }\end{array}$ & $\begin{array}{l}\text { In-field: bunch count and } \\
\text { total weight, photos of } \\
\text { two bunches, 3-5 berries } \\
\text { stored }\end{array}$ \\
Lab: -- \\
\hline $\begin{array}{l}\text { Grape } \\
\text { berry }\end{array}$ & $\begin{array}{l}\text { 3-5 berries were collected from each of } \\
\text { the above four vines and were stored in } \\
\text { coolers for measuring diameter, pH and } \\
\text { Brix later in Lab. }\end{array}$ & $\begin{array}{l}\text { In-field: photos } \\
\text { Lab: diameter, } \mathrm{pH}, \\
\text { weight and Brix }\end{array}$ \\
\hline
\end{tabular}


collected from 58 sites, at horizons A, B and C (figure 3) since 2009. Chemical experiments were performed on each soil sample to obtain Sodium (Na), Potassium (K) and Nitrate (NO3) ion concentrations at the sites. The soil samples were collected using a $5-\mathrm{cm}$ diameter cast iron auger. As soon as the soil sample was removed from the auger the soil $\mathrm{pH}$ and temperature were measured using a Field Scout $\mathrm{pH} 110$ Meter Data Logger and soil thermometer, the soil samples were then sealed in clean plastic bags and transported to the lab for further analysis. In the lab the samples were air dried to minimize biological transformation and other chemical reactions. Plant and root material were also removed. The soil samples were then ground and sifted through a $1 \mathrm{~mm}$ sieve, bagged, labelled and stored in a dry and cool place for subsequent chemical experiments. For details on the soil sampling methods and chemical tests conducted see (Perez-Kuroki, et al., 2011).

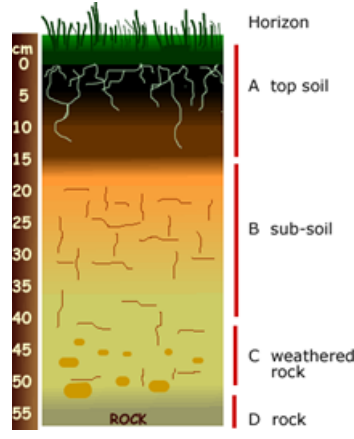

Figure 3. Soil profile showing the different layers sampled

\subsection{Grape bunch and berry sampling}

Grape bunches and berries collected from the four adjacent vines closest to soil sampling sites (figure1) were used in the yield analysis. Grape bunches in each of the vines were counted and weighted at harvest. Samples of 3-5 berries were removed from these harvested bunches, transported to the lab in a cooler and then frozen as lab tests were conducted later. The weight, diameter, $\mathrm{pH}$ and Brix of the thawed berries were measured and are analysed in this research to model the effects of soil nutrients on yield in a spatial context. Grape bunches of each vine and all berries of two bunches were also photographed for future work using image processing techniques to develop berry colour-composition-ripening correlations.

\section{DATA PREPARATION AND METHODOLOGY}

\subsection{Berry attributes}

Berry attributes of grape samples collected in 2011 (468 berries from 39 points) and 2013 (1040 samples from 52 points) were clustered to analyse the major berry attributes. For clustering, SOM methods were implemented using "Viscovery", commercial software (www.viscovery.net). Rule extraction function JRip of WEKA (www.cs.waikato.ac.nz/ml/weka/) was then performed to extract rules from the berry attributes in different clusters.

\subsection{Plant yield and soil nutrients}

Data on soil nutrients, total yield of vines adjacent to soil sampled points and averages of berry $\mathrm{pH}$ and Brix were integrated into one file to perform geostatistical analyses. Bramley, et al., (2011) used a "juice index", tasters' rating (on a 5 point scale) to describe and relate the berry composition in terms of $\mathrm{pH}$, Brix, soluble solids and titratable acid, from sample vines over the berry ripening period. This juice index test was not performed in this work. Instead plant total yield and average berry attributes were clustered to identify the main juice index classes based on the attributes alone. Self-organising map ( $\left.\mathrm{SOM}^{1}\right)$ methods were used to cluster and identify the main classes for this purpose. Finally, geostistical analyses were performed to see the spatial variability and the correlations between soil, topography and yield within this vineyard.

\section{RESULTS AND DISCUSSION}

The results obtained from profiling and analysing SOM berry classes (of sampled berry attributes) are presented. Subsequently, geostatistical analyses performed on a juice index created using plant total yield and averages of berry attributes, against soil data and elevation of 2011 and 2013 are discussed.

\subsection{Berry classes and patterns}

In examining the SOM berry classes (figure 4) for 2011 (468 samples) and 2013 (1040 samples), the following observations were made:

\footnotetext{
1 SOMs first introduced by Kohonen in the late 1980s, are two layered feed forward artificial neural networks with an unsupervised algorithmic training. They are useful in projecting multidimensional input data onto low dimensional displays while preserving the intrinsic properties in the raw data, the feature enhances the detection of previously unknown knowledge in the form of patterns, structures, correlations and relationships. (Kohonen, T., Self-Organization and Associative Memory, New York, Springer-Verlag, 1988.)
} 
Shanmuganathan et al., Climate effects on grape production and quality at Kumeu, New Zealand

- $\quad$ Brix range in 2013 berries was quite high when compared with that of 2011. The range for 2013 was 15-29.2 whereas for 2011 it was 11.4-23.2.

- Berry weight ranges show an opposite trend, they were higher in 2011 clusters (0.86-2.81 grams) than those in 2013 (0.06-2.1 grams). The different class ranges can be seen in figure 4 graphs.

- $\quad$ Berry pH ranges show considerable variability; in 2011 it was (3.23-3.75) and in 2103 (2.99-4.32).

Based on the JRip (WEKA function) the conditions for SOM clusters that consist of high brix for 2011 are clusters 3, 5 and 7, with berry attributes: higher brix, lower berry weight and lower elevation (terroir). The SOM cluster C7 from 2011 (Figure 5, top) has one of the highest brix levels $(>=19$ ) but from a relatively low elevation $(<=35 \mathrm{~m})$ and berry weight $(<=1.41 \mathrm{gms})$. The first three JRip rules (Figure 5 top) were met in 42 instances and together describe cluster C7. The 4th and 5th rules that describe cluster C3, were met in 46 of 48 instances. Instances in $\mathrm{C} 3$ require an elevation of $<=35 \mathrm{~m}$ and a berry $\mathrm{pH}$ of 3.48 . The rules 6-9 describe $\mathrm{C} 3$ and the required cluster conditions are: high brix, lower berry weight and again lower elevation. Cluster two with 70 instances has a mid-range brix value and berry weight greater than 1.32grams. The remaining clusters are characterised by low brix $<=15.2,<=16.2,<=17.2$ and $<=18.2$ ) and higher berry weight.

The berry weight and pH ranges for clusters with higher brix appear to be the same for both 2011 and 2013. But for 2013 SOM clusters C2 and C6 contain instances with high brix values and the sample sites are at a higher elevation as opposed to the 2011 clusters. This opposite trend in the relationship between brix and elevation for 2011 and 2013 suggests that the blocks located at lower lying areas might have been affected by the severe frost in September 2012. This frost occurred at a critical time when the vine buds begin to swell and burst. The significant changes caused to berry brix and $\mathrm{pH}$ by this event can be seen in a spatial context in figure 6 maps.
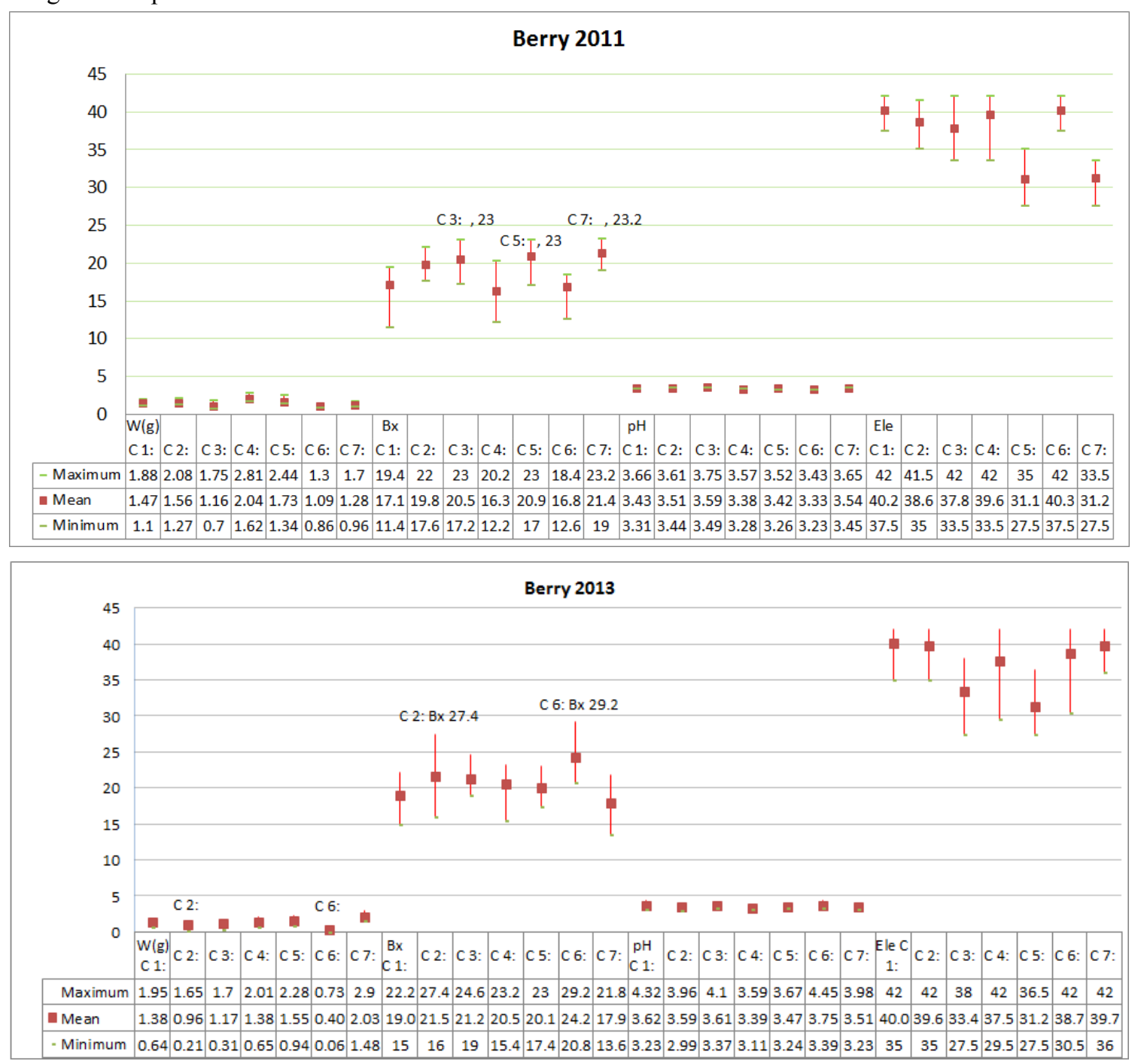

Figure 4. Grape berry classes based on berry weight (g), Brix, berry pH 2011 (top) and 2013 (bottom) 


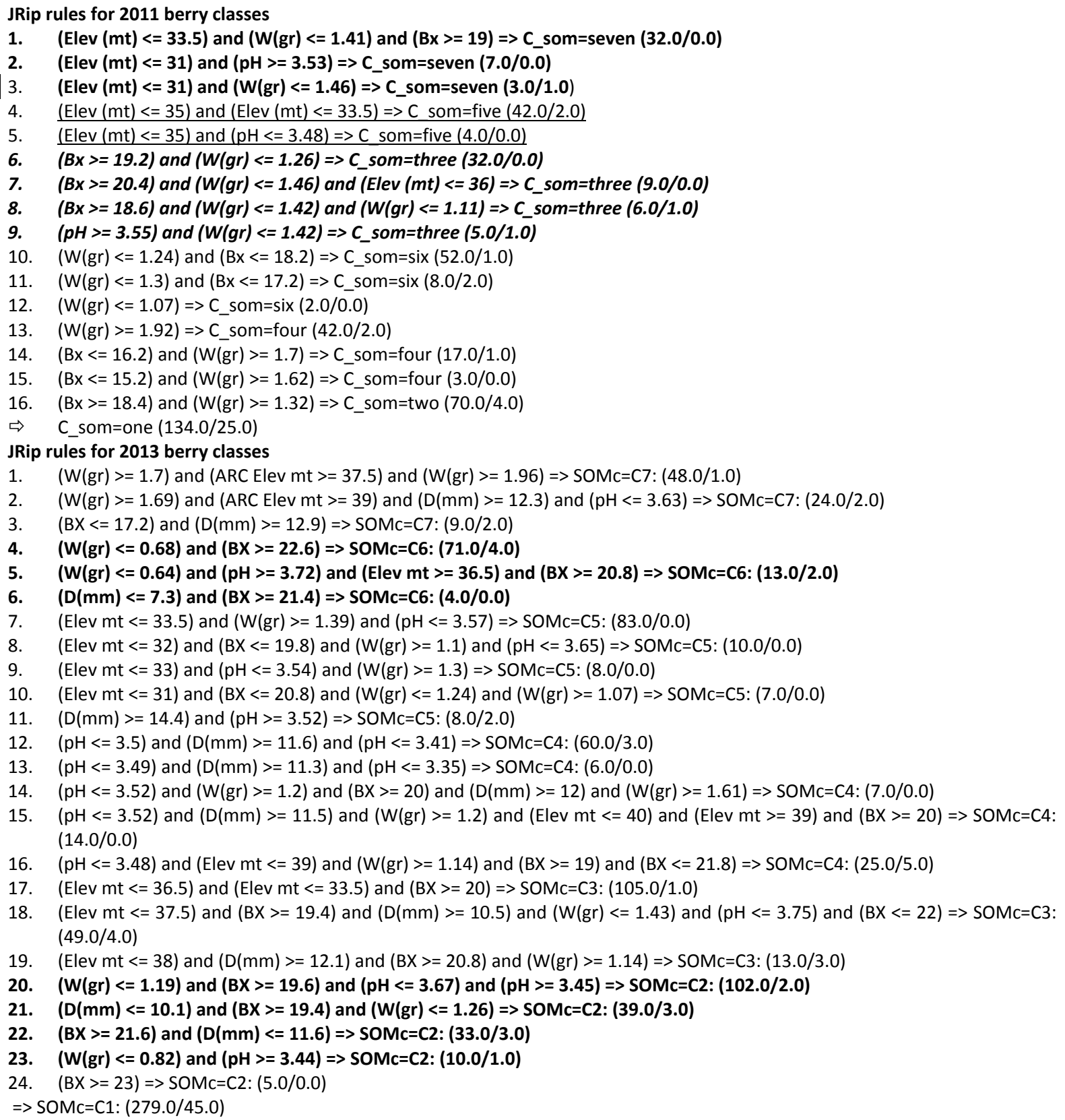

Figure 5. Berry classes (SOM clusters of berry attributes: weight (g), Brix, pH, diameter and elevation

\subsection{Geostatistical analysis}

Hot spot analysis, explanatory and ordinary least square (OLS) regressions were performed on the juice index class (figure 7) generated by SOM clustering of total yield $(\mathrm{Kg})$ and vine averages of berry weight, Brix and $\mathrm{pH}$, against soil data obtained before the growing season and site elevation for the 2011 and 2013 data.

\subsection{Soil properties against juice index classes of 2011 and 2013}

Hot spot analysis results of the 2011 juice index classes (12 SOM clusters created with site elevation and vine total yield, averages of berry weight, brix and $\mathrm{pH}$ (figure 6 top), produced 4 spots ( 2 hot spots and 2 cold spots) with a z-scores of 1.96 standard deviation above and below the mean respectively, at a confidence level of $95 \%$. Explanatory regressions were then performed using the soil variables (as independent variables) and yield (as the dependent variable) showed co-linearity between elevation and $\mathrm{NO}_{3}$ with no passing models. However, when performed without $\mathrm{NO}_{3}$, but with all other independent variables included a passing model with elevation and Na as predictors was produced. The OLS test on the passing model had no spatial autocorrelation among residuals (Moran rule test results showed a random distribution in the OLS residuals). 

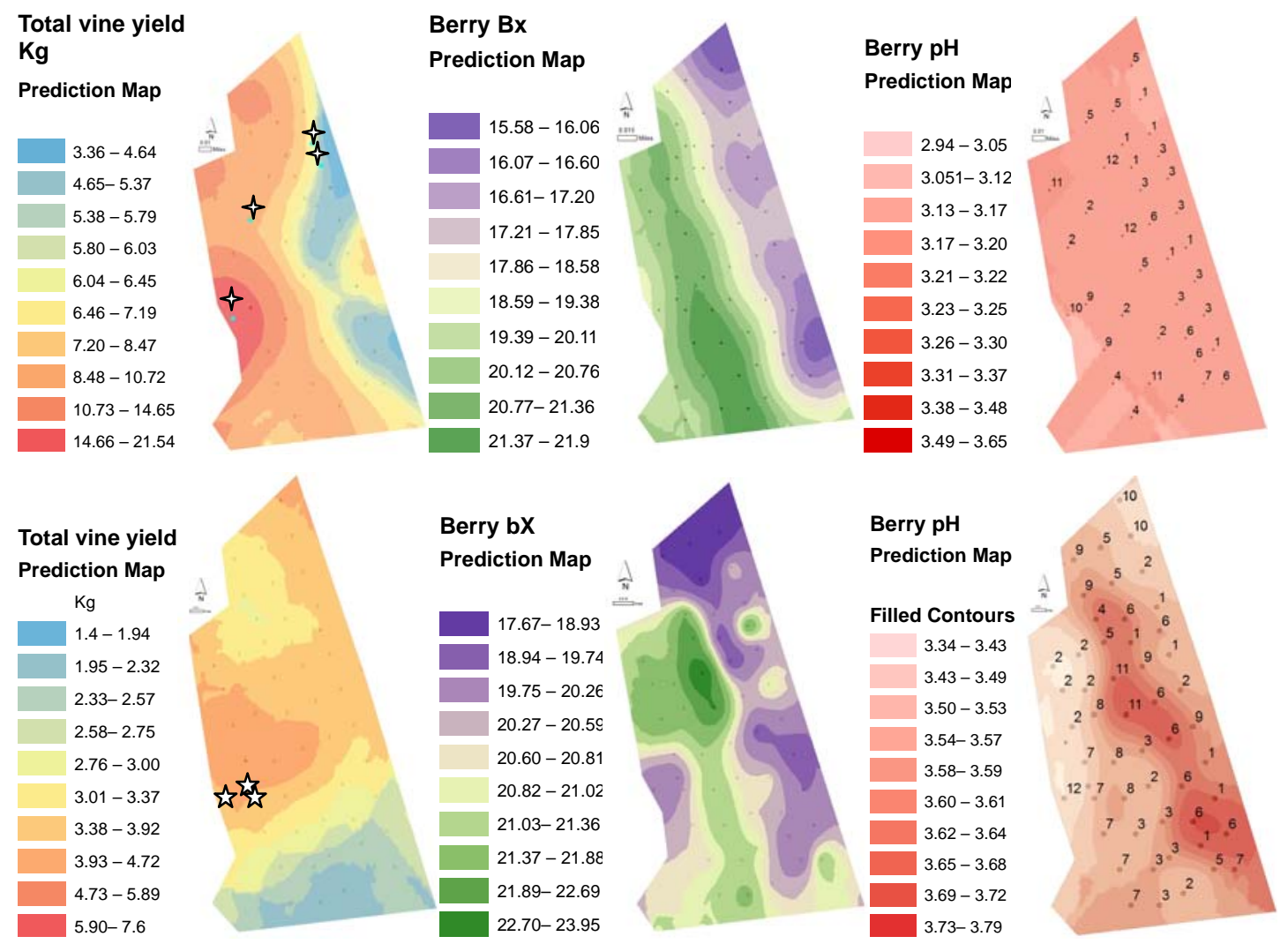

Figure 6. Grape crop distribution in total yield weight $(\mathrm{Kg})$, berry $\mathrm{Brix}(\mathrm{Bx} / \mathrm{bX})$ and $\mathrm{pH}$ (with juice index) in 2011 (top) and 2013 (bottom). The + and * marks show the hot spots with the $\mathrm{z}$-score $<1.96$ at $<0.05 \mathrm{p}$ value for 2011 and with std. deviation $<2.58$ at $<0.01 \mathrm{p}$-value for 2013 respectively.

The same tests were performed on the 2013 data set and the hot spot test produced three hot spot points with a z-score of 2.58 above the mean at confidence level 99\% (figure 6 bottom). However, explanatory regression performed on 2013 data set did not produce any passing models and no strong predictors were found using OLS regression either. This means that there was some other explanatory variable(s) for the 2013 juice index classes. It is possible that the severe forest experienced for that season affected the development of the berries and subsequently the juice. For 2013 the yield was low and that this reduction in yield was attributed by the wine grower to the frost events experienced in September 2012.

The juice index classes derived for 2013 show that though the yield was relatively low and berries were smaller than usual, but their Brix values were high compared with the 2011 harvest for both the Chardonnay and Pinot Noir varieties (figures 6 and 7). For the 2011 Pinot Juice index classes identified (C1, C3, C5, C6 and $\mathrm{C} 7$ in figure 7 top graph), variability in elevation, berry weight and $\mathrm{pH}$ was found to be insignificant, and the Brix and $\mathrm{pH}$ values were within small ranges (15.5-17.85 and 3.2-3.33 respectively). However among the the 2013 Pinot classes, C2 and C7 (figure 7 bottom), show that the vines at low elevations have produced grapes with higher Brix values with low plant yield and berry weight, a deviation observed in 2013 possibly due to the frost experienced in the early growing season.

\section{CONCLUSIONS}

The paper investigated the effects of seasonal climate and soil on the yield of a commercial vineyard in Kumeu, Western Auckland, NZ using soil and grapevine crop sampling data gathered in 2011 and in 2013 in a spatial context using geostatistical methods. The results show the spatial variability within the vineyard especially, the areas that produce berries with high Brix under normal seasonal climatic conditions as was the case with 2011 data. The 2013 yield data and its distribution show the effects of severe frost on the total vine yield, berry attributes (Brix and $\mathrm{pH}$ ) and the patches that are more prone to damage by frost.

More research is warranted to establish the exact climatic conditions that impact on grapevine phenology and productivity in a spatial context that could be of use to the vineyard management decision making. 

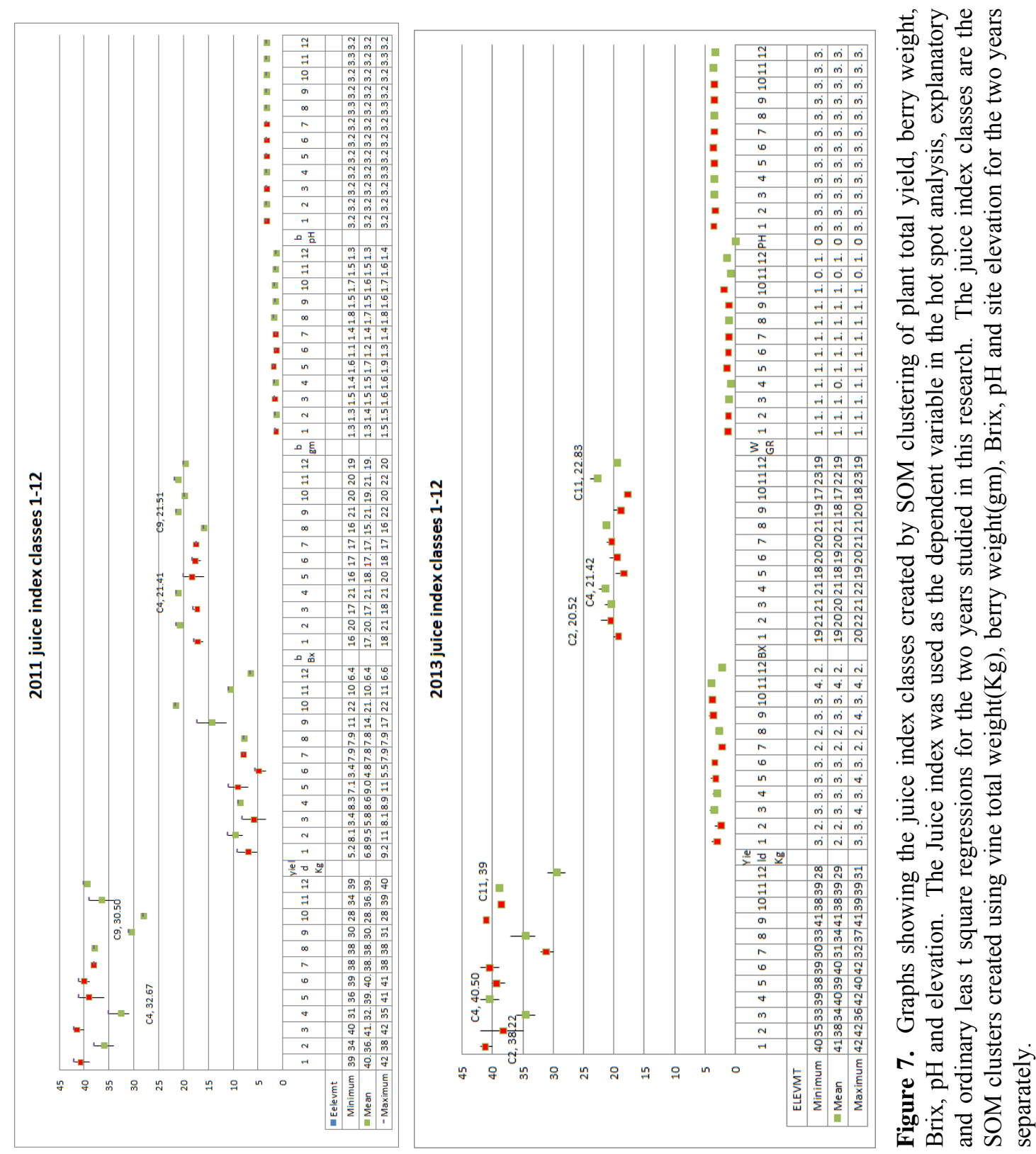

\section{ACKNOWLEDGMENTS}

Kumeu River Wines Michael Brajkovich (Master Winemaker) and management are acknowledged for their support and knowledge given in conducting soil composition and grapevine yield sampling.

\section{REFERENCES}

Bramley, R. G. V., Trought, M. C. T. \& Praat, J. P. (2011). Vineyard variability in Marlborough, New Zealand: characterising variation in vineyard performance and options for the implementation of Precision Viticulture. Australian Journal of Grape and Wine Research 17 (1) $72-78$ http://dx.doi.org/10.1111/j.1755-0238.2010.00119.x.

Perez-Kuroki, A., Shanmuganathan, S., Scannavino Jr, F., Sallis, P., \& Narayanan, A. (2011). Establishing the correlation between soil and crop production to optimize wine quality In proceedings of 19th International Conference on Modelling and Simulation (MODSIM 2011), Perth/Australia 12-16 December 2011, 1132-1138.

Shanmuganathan, S., Narayanan, A. \& Robinson, N., 2011. A cellular automaton framework for within-field vineyard variance and grape production simulation. In proceedings of the 7 th International Conference on Natural Computation Editors: Ding Y, Wang H, Xiong N, Hao K, Wang L., Shanghai, China, 26 - 28 Jul 2011. Vol 3 IEEE Conference Record Number for ICNC'11.ISBN 978-1-4244-9951-9, 1456-1461. 